\title{
Amorphouslike diffraction pattern in solid metallic titanium
}

Wang, Y.; Fang, Y.Z.; Kikegawa, T.; Lathe, C.; SaksI, K.; Franz, H.; Schneider, J.R.; Gerward, Leif; Wu, F.M.; Liu, J.F.

Total number of authors:

11

Published in:

Physical Review Letters

Link to article, DOI:

10.1103/PhysRevLett.95.155501

Publication date:

2005

Document Version

Publisher's PDF, also known as Version of record

Link back to DTU Orbit

Citation (APA):

Wang, Y., Fang, Y. Z., Kikegawa, T., Lathe, C., Saksl, K., Franz, H., Schneider, J. R., Gerward, L., Wu, F. M., Liu, J. F., \& Jiang, J. Z. (2005). Amorphouslike diffraction pattern in solid metallic titanium. Physical Review Letters, 95(15), 155501. https://doi.org/10.1103/PhysRevLett.95.155501

\section{General rights}

Copyright and moral rights for the publications made accessible in the public portal are retained by the authors and/or other copyright owners and it is a condition of accessing publications that users recognise and abide by the legal requirements associated with these rights.

- Users may download and print one copy of any publication from the public portal for the purpose of private study or research.

- You may not further distribute the material or use it for any profit-making activity or commercial gain

- You may freely distribute the URL identifying the publication in the public portal 


\title{
Amorphouslike Diffraction Pattern in Solid Metallic Titanium
}

\author{
Y. Wang, ${ }^{1}$ Y.Z. Fang, ${ }^{2}$ T. Kikegawa, ${ }^{3}$ C. Lathe, ${ }^{4}$ K. Saksl, ${ }^{4}$ H. Franz,${ }^{4}$ J. R. Schneider, ${ }^{4}$ L. Gerward, ${ }^{5}$ F. M. Wu, ${ }^{2}$ \\ J. F. Liu, ${ }^{1}$ and J. Z. Jiang ${ }^{1, *}$ \\ ${ }^{1}$ Laboratory of New-Structured Materials, Department of Materials Science and Engineering, \\ Zhejiang University, Hangzhou, 310027, People's Republic of China \\ ${ }^{2}$ Department of Physics, College of Mathematics and Physics, Zhejiang Normal University, Jinhua, 321004, \\ Zhejiang, People's Republic of China \\ ${ }^{3}$ Photon Factory, Institute for Materials Structure Science, High Energy Accelerator Organization, 1-1, \\ Oho, Tsukuba 305-0801, Japan \\ ${ }^{4}$ HASYLAB am DESY, Notkestrasse 85, D-22603 Hamburg, Germany \\ ${ }^{5}$ Department of Physics, Technical University of Denmark, DK-2800 Lyngby, Denmark \\ (Received 16 May 2005; published 3 October 2005; corrected 3 October 2005)
}

\begin{abstract}
Amorphouslike diffraction patterns of solid elemental titanium have been detected under high pressure and high temperature using in situ energy-dispersive x-ray diffraction and a multianvil press. The onset pressure and the temperature of formation of amorphous titanium is found to be close to the $\alpha-\beta-\omega$ triple point in the $P$-T phase diagram. Amorphous Ti has been found to be thermally stable up to $1250{ }^{\circ} \mathrm{C}$ for at least $3 \mathrm{~min}$ at some pressures. By analyzing the conditions for producing amorphous elemental $\mathrm{Zr}$ and $\mathrm{Ti}$, we observed a multi-phase-point amorphization phenomenon for preparing single-element bulk amorphous metals. The results reported may open a new way to preparing single-element bulk amorphous metals with a high thermal stability.
\end{abstract}

DOI: 10.1103/PhysRevLett.95.155501

PACS numbers: 61.43.Dq, 62.50.+p, 64.60.My, 64.70.Kb

Since the discovery of new glassy systems, based on multicomponent alloys, in the early 1990s, bulk metallic glasses have been extensively studied because of their extraordinary mechanical and magnetic properties [1]. Promising technological applications seem to be within reach for this novel class of materials. Thus, the study of bulk metallic glasses has become a most active research field in the past decade [2-11]. Bulk metallic glasses produced so far usually contain three or more elements [1]. They are usually produced by the copper-mold method, typecasting the multicomponent liquid alloy to the mold, and rapidly cooling the liquid alloy to ambient temperature. Complex compositions seem to be necessary in order to inhibit crystallization of the liquid phase during the cooling of the melt. The preparation of single-element and binary bulk metallic glasses is of great interest, fundamentally as well as technologically. However, the equilibrium melt viscosity of a pure metal is usually 3 orders of magnitude smaller than that of an amorphous alloy, and current technology has yet to reach cooling rates in excess of $10^{10}-10^{12}{ }^{\circ} \mathrm{C} / \mathrm{s}$ to make pure metals amorphous [12]. This means insurmountable difficulties to produce bulk glassy materials of pure metals [13]. Zhang and Zhao [14] recently reported the production of bulk metallic glass from pure zirconium metal under high pressure and high temperature. But, the origin of the formation of the pressure-induced elemental metal glass is still unexplained. In this Letter, amorphouslike diffraction patterns of solid elemental titanium have been detected under high pressure and high temperature using in situ energydispersive $\mathrm{x}$-ray diffraction (XRD) and a multianvil press.
The onset pressure and the temperature of formation of amorphous titanium is found to be close to the $\alpha-\beta-\omega$ triple point in the $P-T$ phase diagram. Amorphous Ti, though crystallized when quenched to ambient temperature, has been found to be thermally stable up to $1250^{\circ} \mathrm{C}$ for at least $3 \mathrm{~min}$ at some pressures. By analyzing the conditions for producing amorphous elemental $\mathrm{Zr}$ and $\mathrm{Ti}$, we observe a multi-phase-point amorphization phenomenon for preparing single-element bulk amorphous metals. The results reported may open a new way to preparing single-element bulk amorphous metals with a high thermal stability.

At normal conditions, the group 4 (IVB) transition metals $\mathrm{Ti}, \mathrm{Zr}$, and $\mathrm{Hf}$ all crystallize in the close-packed hexagonal structure, called the $\alpha$ phase. At high temperature and ambient pressure, they transform to the body-centered cubic structure or the $\beta$ phase at temperatures of $882^{\circ} \mathrm{C}$, and $863^{\circ} \mathrm{C}$ for $\mathrm{Ti}$ and $\mathrm{Zr}$, respectively, before reaching the melting temperature [15]. At ambient temperature and high pressure, they undergo a structural transformation to the so-called $\omega$ phase (a hexagonal structure with space group $P 6 / \mathrm{mmm}$ ) at transition pressures of 2.0 and $2.2 \mathrm{GPa}$ for Ti and $\mathrm{Zr}$, respectively [15]. At even higher pressures, both $\mathrm{Zr}$ and $\mathrm{Hf}$ transform to the $\beta$ phase. In Ti, no $\beta$ phase has been observed up to $216 \mathrm{GPa}$ [16]. Zhang and Zhao [14] discovered that an amorphous phase appeared from high purity $\omega-\mathrm{Zr}$ at $650^{\circ} \mathrm{C}$ and $5.3 \mathrm{GPa}$ by performing in situ high-temperature and high-pressure $\mathrm{x}$-ray diffraction using synchrotron radiation. However, the amorphous phase crystallized when quenched to room temperature. At higher pressures (6.4 and $8.6 \mathrm{GPa}$ ), the amorphous phase 
was formed from $\beta$-Zr at 700 and $625^{\circ} \mathrm{C}$, respectively. This amorphous phase was found to have superior thermal stability, no precipitation of any crystalline phase occurred even at temperatures up to $1000{ }^{\circ} \mathrm{C}$. In contrast, crystallization happens when conventional amorphous alloys are heated to about $500{ }^{\circ} \mathrm{C}$ for a few minutes, even for extremely good glass formers, such as the $\mathrm{Pd}_{40} \mathrm{Ni}_{10} \mathrm{Cu}_{30} \mathrm{P}_{20}$ alloy [17] and Vit1 $\left(\mathrm{Zr}_{41.2} \mathrm{Ti}_{13.8} \mathrm{Cu}_{12.5} \mathrm{Ni}_{10} \mathrm{Be}_{22.5}\right)$ [18]. This problem seems to be absent in the elemental metallic glass with its extraordinary thermal stability. We note that the thermally stable amorphous $\mathrm{Zr}$ appeared only in a limited pressure range in the work of Zhang and Zhao [14]. No amorphous phase was produced at $4.3 \mathrm{GPa}$ even when the sample was heated to $900^{\circ} \mathrm{C}$. At pressures higher than $9 \mathrm{GPa}, \mathrm{Zr}$ was only partially transformed to the amorphous phase, the diffraction pattern being dominated by the $\beta$ phase. All of these facts indicate that pressure is a key issue for the formation of an amorphous phase from a pure metal. Moreover, we notice that the amorphous phase of $\mathrm{Zr}$ is produced in a pressure-temperature range close to the triple point at about $5.5 \mathrm{GPa}$ and $700^{\circ} \mathrm{C}$ in the phase diagram of $\mathrm{Zr}$ [19-21]. The amorphization of elemental $\mathrm{Zr}$ could be explained in the following way. Close to the triple point, Gibbs free energies of the $\alpha, \beta$, and $\omega$ phases are nearly equal. Therefore, the $\mathrm{Zr}$ atoms can choose randomly between any of the three crystal structures, and as an average result they tend to arrange themselves in a disordered way. This may be called a phase-confusion model. A similar element-confusion model was suggested for multicomponent systems [5]. Gibbs free energy of the amorphous phase might be lower than that of any of the crystal phases when its entropy is maximal. If this argument is true, we should be able to turn any multiphase

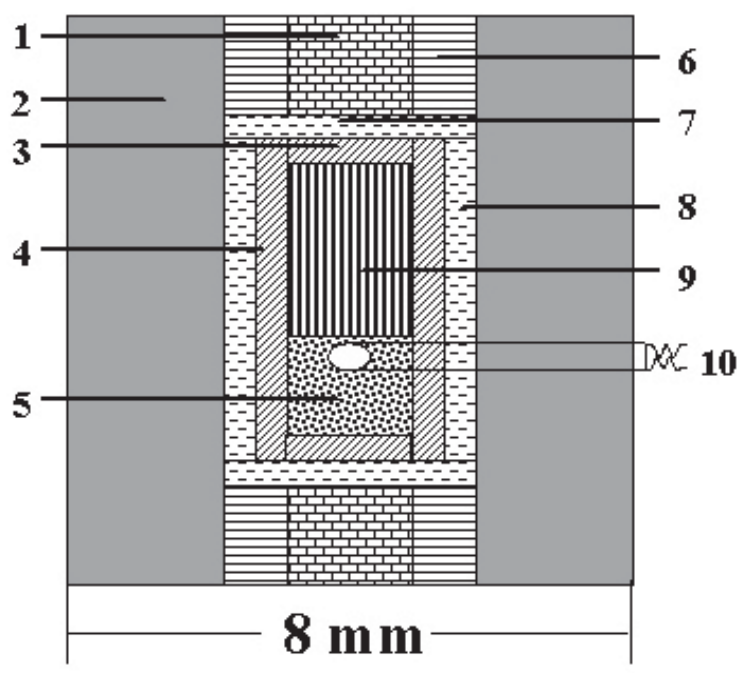

FIG. 1. Schematic map of the sample assembly for highpressure and high-temperature $\mathrm{x}$-ray powder diffraction studies. (1) Pyrophyllite disk. (2) Boron-epoxy cube. (3) BN disk. (4) BN container. (5) NaCl. (6) Copper ring. (7) Graphite disk. (8) Graphite heater. (9) Ti rod. (10) Thermocouple. metal element into an amorphous phase near a multiphase point in the pressure-temperature phase diagram. In particular, it should be possible to produce amorphous $\mathrm{Ti}$ and Hf, which belong to the same group 4 (IVB) as Zr. To test our hypothesis, we have investigated highly pure Ti metal $(99.99 \%)$ at pressures and temperatures up to $7.2 \mathrm{GPa}$ and $1300^{\circ} \mathrm{C}$. A similar method, at triple point to synthesize bulk amorphous Si was also suggested by Angell [22].

In situ high-temperature and high-pressure energydispersive XRD spectra were recorded using a multianvil press (MAX 80) and synchrotron radiation at HASYLAB in Hamburg, Germany [23]. The sample chamber is shown in Fig. 1. The central part consists of a cylindrical boron nitride container with an internal diameter of $1 \mathrm{~mm}$. The upper half is filled with the sample (1 $\mathrm{mm}$ in diameter and $1 \mathrm{~mm}$ in length), the lower half with $\mathrm{NaCl}$ powder for pressure calibration. The cubic chamber is compressed by six tungsten carbide anvils in a large hydraulic press. Electric current is sent through a graphite heater via two appropriate anvils. The temperature, which is stable within $\pm 1{ }^{\circ} \mathrm{C}$, is measured by means of a thermocouple. Samples were held for about $10 \mathrm{~min}$ at a given temperature and then heat up to a next temperature with a step about $50{ }^{\circ} \mathrm{C}$ in the temperature range of $50-600^{\circ} \mathrm{C}$ and about $20-10^{\circ} \mathrm{C}$ in the temperature range of $600-1300^{\circ} \mathrm{C}$ with about $1 \mathrm{~min}$. Immediately thereafter, the measurements were started again. Above $1100^{\circ} \mathrm{C}$ samples were held for about $3 \mathrm{~min}$ to avoid gasket explosion. The rod shape of the sample in all experiments remains after high-pressure (up to $7.2 \mathrm{GPa}$ ) and high-temperature (up to $1300^{\circ} \mathrm{C}$ ) treatments. This indicates that melting behavior of Ti metal can be ruled out in the conditions used here.

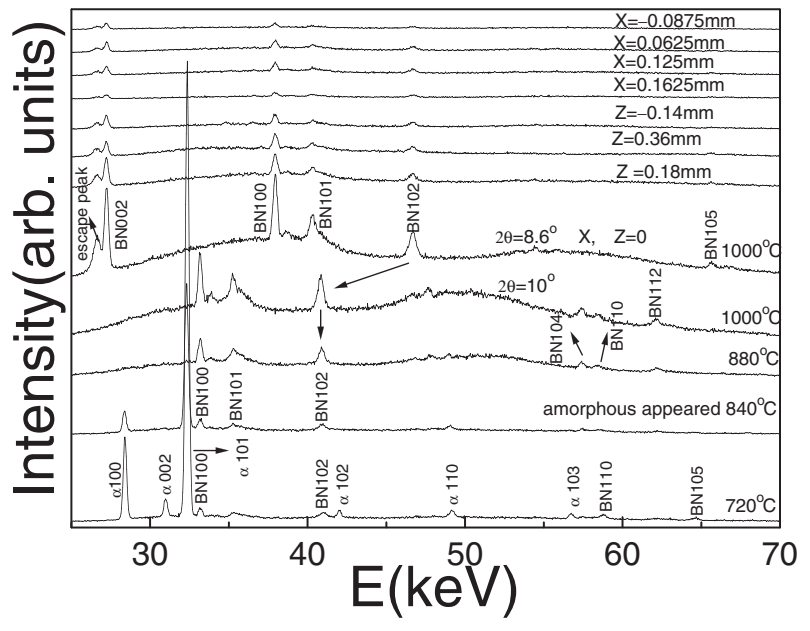

FIG. 2. In situ energy-dispersive $\mathrm{x}$-ray powder diffraction patterns recorded at various temperatures for $\mathrm{Ti}$ rod at $6.3 \mathrm{GPa}$ $\left(2 \theta=10^{\circ}\right)$ together with patterns using $2 \theta=8.6^{\circ}$ at $1000^{\circ} \mathrm{C}$ and various sample positions (along rod longitudinal $Z$ axis and transversal $X$ axis). The escaped peaks and a few Bragg peaks from $\mathrm{BN}$ were marked. The patterns for the sample at various positions were recorded for short times. 
The original $\alpha$-phase sample was compressed at room temperature and then heated to high temperatures at constant pressure. Figure 2 shows XRD spectra recorded at various temperatures during an isobaric run at $6.3 \mathrm{GPa}$. The sample remains in the $\alpha$ phase at $100^{\circ} \mathrm{C}$, but the $\omega$ phase appears at $150{ }^{\circ} \mathrm{C}$. Upon further heating, the sample becomes a mixture of $\alpha$ and $\omega$ phases in varying proportions. The amount of the $\alpha$ phase first decreases and then increases, so that the sample is back to pure $\alpha$ phase at $720^{\circ} \mathrm{C}$. Linewidths of Bragg peaks for $\alpha$ and $\omega$ phases at different temperatures are similar, indicating average crystallite sizes are similar during the heating treatments. The amorphouslike diffraction pattern (hereafter called amorphous phase) appears at $840{ }^{\circ} \mathrm{C}$, and the Ti sample is completely amorphous at $880^{\circ} \mathrm{C}$. The amorphous phase is found to be stable upon further heating to $1000^{\circ} \mathrm{C}$. To confirm that the sample is amorphous throughout, we have (1) changed angle from $2 \theta=10^{\circ}$ to $2 \theta=8.6^{\circ}$ and
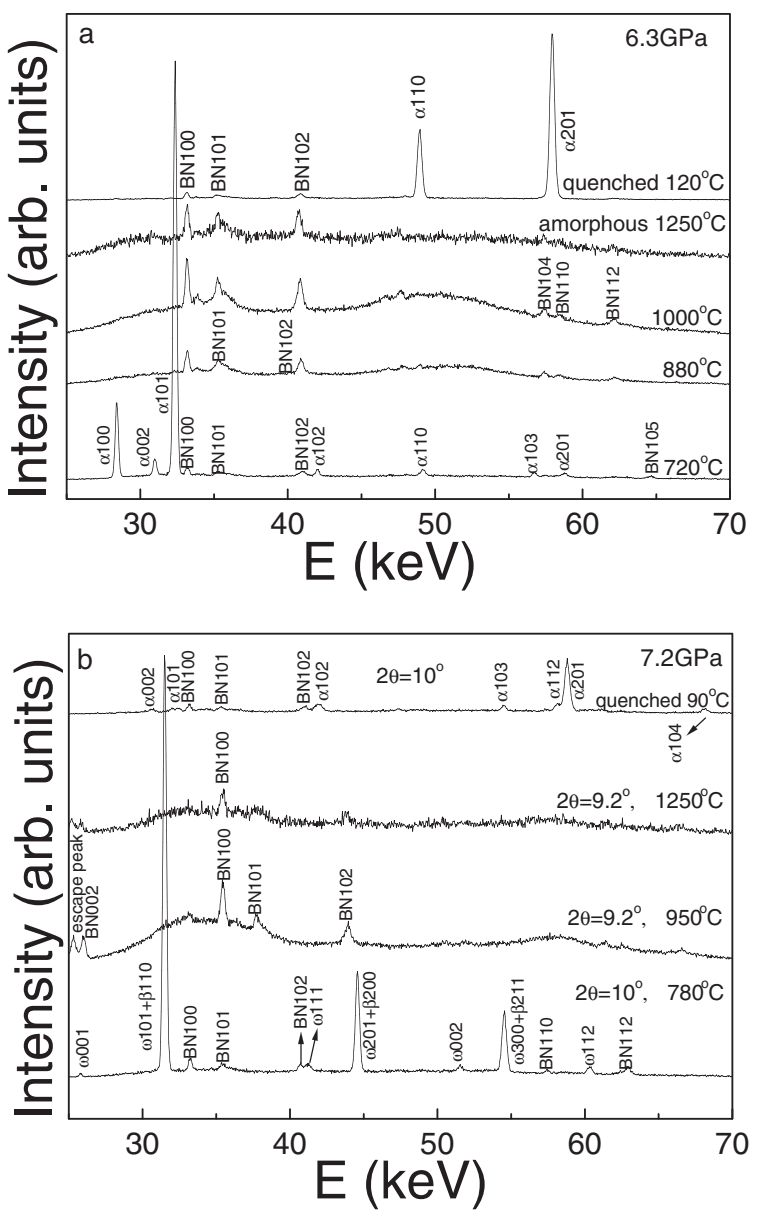

FIG. 3. In situ energy-dispersive $\mathrm{x}$-ray powder diffraction patterns recorded for $\mathrm{Ti}$ rod under (a) $6.3 \mathrm{GPa}\left(2 \theta=10^{\circ}\right)$ and (b) $7.2 \mathrm{GPa}\left(2 \theta=10^{\circ}\right.$ and $\left.2 \theta=9.2^{\circ}\right)$ and at various temperatures together with patterns recorded for quenched samples. The escaped peaks and a few Bragg peaks from BN were marked. The patterns at $1250{ }^{\circ} \mathrm{C}$ were recorded for about $3 \mathrm{~min}$ to avoid gasket explosion.
(2) made a lateral scanning at $1000{ }^{\circ} \mathrm{C}$ with the incident $\mathrm{x}$-ray beam of $0.5 \times 0.25 \mathrm{~mm}^{2}$ cross section in Fig. 2. To further explore the thermal stability, the Ti sample was heated to $1250^{\circ} \mathrm{C}$ for about 3 min and as shown in Fig. 3. It is still amorphous.

In a run at the higher pressure $7.2 \mathrm{GPa}$, the $\omega$ phase appeared already at ambient temperature. The amount of $\alpha$ phase was reduced during the heating process and was zero at $150{ }^{\circ} \mathrm{C}$. The precise position of the $\alpha-\omega$ transition needs further study. At $780^{\circ} \mathrm{C}$ there is a mixture of $\omega$ and $\beta$ phases, and at $920^{\circ} \mathrm{C}$ the formation of the amorphous phase is observed (Fig. 3). The amorphous phase is stable at $1250^{\circ} \mathrm{C}$ for at least $3 \mathrm{~min}$. Upon cooling, the samples in the 6.3 and $7.2 \mathrm{GPa}$ runs transform to the crystalline $\alpha$ phase at 120 and $90^{\circ} \mathrm{C}$, respectively, as shown in Fig. 3. In order to further confirm the usability of our multi-phasepoint method, we have made several additional runs at 4.4, $5.3,5.7,6.1,6.5$, and $6.6 \mathrm{GPa}$. The formation of amorphouslike diffraction patterns of solid Ti rod with a diameter of $1 \mathrm{~mm}$ was observed in all of these experiments. Figure 4 shows the phase diagram of Ti in $P-T$ space. There is a large scattering of reported positions of the $\alpha-\beta-\omega$ triple point as determined by various experimenters using static or shock-wave compression: $\left(640 \pm 50{ }^{\circ} \mathrm{C}\right.$, $8 \pm 0.7 \mathrm{GPa})$ [15], $\left(827^{\circ} \mathrm{C}, 9 \mathrm{GPa}\right)[21],\left(690 \pm 20^{\circ} \mathrm{C}\right.$, $5.5 \pm 0.5 \mathrm{GPa}$ ) [24]. Many problems have to be solved in the phase diagram of Ti: the slope of the $\beta-\omega$ transition line, the $\alpha-\omega$ and $\alpha-\beta$ boundaries, etc. Anyway, we have made it plausible that the glass formation occurs close to the triple point. In all of our experiments, we were unable to retain the amorphous phase when quenching to room temperature and zero pressure. There may be two reasons.

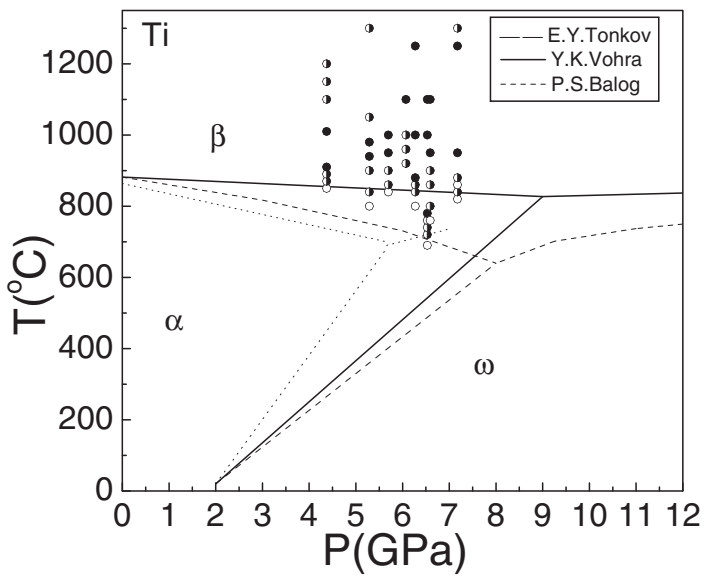

FIG. 4. Phase diagram of $\mathrm{Ti}$, obtained in compression and heating mode. Circle symbols are obtained from present work. Filled circles denote amorphous phase, and partially filled circles are a mixture of amorphous and crystalline phases. Solid lines, broken lines, and dotted lines are from data in Refs. [15,21,24], respectively. $\quad \alpha=$ close-packed hexagonal structure,$\quad \beta=$ body-centered cubic structure, and $\omega=$ hexagonal structure with space group $P 6 / \mathrm{mmm}$. 
First, the onset pressures for amorphization are lower than those of Zhang and Zhao [14]. Second, we have cooled the sample isobaric and then decompressed it. During the isobaric cooling, the sample is far from the triple point, and it will crystallize.

It should be mentioned that phonon dispersion measurements of the high-temperature $\beta$ phase of Ti $[25,26], \mathrm{Zr}$ [27], and Hf [28] reveal phonon anomalies at the longitudinal $L \frac{2}{3}(1,1,1)$ mode and the transverse $T_{1} \frac{1}{2}(1,1,0)$ mode. The former mode displaces the $\beta$ lattice toward the high-pressure $\omega$ phase, and the latter one shifts the $\beta$ planes into the stacking sequence of the low-temperature $\alpha$ phase. The $\beta$ phase, stabilized mainly by the excess vibrational entropy, has a fast self-diffusion dominated by atomic jumps into nearest-neighbor vacancies. Although the phonon dispersion measurements [25-28] were carried out at ambient pressure, it might indicate that at around the $\alpha-\beta-\omega$ triple point of group 4 (IVB) transition metals Ti, $\mathrm{Zr}$, and Hf, large atomic displacements might cause topological disorder of atomic arrangements with a high value of entropy. Consequently, it results in the multi-phasepoint amorphization phenomenon, as observed in the present work and Ref. [14].

In conclusion, we observe amorphouslike diffraction patterns for the solid elemental Ti rod with a diameter of $1 \mathrm{~mm}$ at high-pressure and high-temperature conditions close to the triple point in the $P-T$ phase diagram of the investigated element using in situ high-temperature and high-pressure energy-dispersive XRD. The Ti amorphous phase is found to have a superior thermal stability compared with conventional multielement amorphous alloys. A multi-phase-point amorphization phenomenon is proposed for forming single-element bulk amorphous phase, which has been applied to $\mathrm{Ti}$ and $\mathrm{Zr}$ metals and can probably also be applied to other multiphase metal elements into an amorphous phase near a multiphase point in the pressure-temperature phase diagram. Thus, the method may open new routes for producing and understanding bulk amorphous alloys. It is the aim of this work to stimulate further theoretical and experimental works to shed light on the origin of the formation of amorphouslike diffraction patterns in solid single elements, Ti and Zr.

The authors thank the synchrotron radiation laboratories of HASYLAB in Hamburg, Germany; KEK in Japan; BSRF in Beijing, and NSRL in Hefei, People's Republic of China; MAXlab in Lund, Sweden; and SPring8 in Japan for use of their facilities; as well as C.A. Angell for valuable discussions about the multi-phase-point amorphization phenomenon at the ISMANAM-2005 meeting. Financial support from the National Natural Science Foundation of China (Grants No. 50341032 and
No. 50425102), the Ministry of Science and Technology of China (Grants No. 2004/249/37-14 and No. 2004/250/ 31-01A), the Ministry of Education of China, and Zhejiang University is gratefully acknowledged.

*Author to whom correspondence should be addressed. Electronic address: jiangjz@zju.edu.cn

[1] A. Inoue, Bulk Amorphous Alloys 2 (Trans Tech Publications, Switzerland, 1998).

[2] W. L. Johnson, MRS Bull. 24, 42 (1999).

[3] A. Inoue, Acta Mater. 48, 279 (2000).

[4] Y. He, S. J. Poon, and G. J. Shiflet, Science 241, 1640 (1988).

[5] A. L. Greer, Science 267, 1947 (1995).

[6] X.-P. Tang, U. Geyer, R. Busch, W. L. Johnson, and Y. Wu, Nature (London) 402, 160 (1999).

[7] G. He, J. Eckert, W. Loser, and L. Schultz, Nat. Mater. 2, 33 (2003).

[8] A. Inoue, B. L. Shen, H. Koshiba, H. Kato, and A. R. Yavari, Nat. Mater. 2, 661 (2003).

[9] J. Schroers and W. L. Johnson, Phys. Rev. Lett. 93, 255506 (2004).

[10] J. Das et al., Phys. Rev. Lett. 94, 205501 (2005).

[11] B. Zhang et al., Phys. Rev. Lett. 94, 205502 (2005).

[12] R. Busch, A. Masuhr, E. Bakke, and W. L. Johnson, Mater. Sci. Forum 269, 547 (1998).

[13] M. F. Ashby and D. R. Jones, Engineering Materials 2: An Introduction to Microstructures, Processing and Design (Pergamon, Oxford, 1986).

[14] J.Z. Zhang and Y.S. Zhao, Nature (London) 430, 332 (2004).

[15] E. Y. Tonkov, High Pressure Phase Transformations (Gordon and Breach Science Publishers, Philadelphia, 1992).

[16] A. L. Kutepov and S.G. Kutepova, Phys. Rev. B 67, 132102 (2003).

[17] N. Nishiyama and A. Inoue, Mater. Trans., JIM 37, 1531 (1996).

[18] A. Peker and W. L. Johnson, Appl. Phys. Lett. 63, 2342 (1993).

[19] H. Xia, S. J. Duclos, A. L. Ruoff, and Y. K. Vohra, Phys. Rev. Lett. 64, 204 (1990).

[20] H. Xia, A. L. Ruoff, and Y. K. Vohra, Phys. Rev. B 44, 10374 (1991).

[21] Y. K. Vohra, J. Nucl. Mater. 75, 288 (1978).

[22] C. A. Angell (private communication).

[23] J.Z. Jiang et al., J. Appl. Phys. 87, 2664 (2000).

[24] P. S. Balog and R. A. Secco, J. Phys. Condens. Matter 11, 1273 (1999).

[25] W. Petry et al., Phys. Rev. Lett. 61, 722 (1988).

[26] W. Petry et al., Phys. Rev. B 43, 10933 (1991).

[27] A. Heiming et al., Phys. Rev. B 43, 10948 (1991).

[28] J. Trampenau et al., Phys. Rev. B 43, 10963 (1991). 